\title{
INVESTIGATIONS OF THE STRUCTURAL CHARACTERISTICS OF CONCRETE PRODUCED FROM RECYCLED AGGREGATES AT VARYING WATER/CEMENT RATIOS
}

\author{
A. W. Otunyo ${ }^{1, *}$ and B. G. Jephter ${ }^{2}$ \\ 1, 2 Department of Civil Engineering, Rivers State University, NKPolu Port HarCourt, Rivers State, NigeRIA. \\ E-mail address: 1 umutuigili@yahoo.com, 2 jephterb@yahoo.com
}

\begin{abstract}
The paper tried to investigate the structural characteristics of concrete produced by partially replacing natural aggregates with recycled aggregates at varying water/cement ratios. The study is basically a laboratory experimental study. Water/cement ratio component of the concrete were varied at $0.40,0.45,0.50,0.55,0.60$; while the natural aggregate was partially replaced with $R C A$ of $0 \%, 15 \%, 30 \%, 45 \%, 60 \%, 75 \%$ and $90 \%$ for concrete productions for 7,14 and 28 days structural characteristics. The densities, water absorption capacity and Compressive Strength of these concretes were determined. The results were presented in graphs and Tables. Results of the study indicate an increased compressive strength at low percentage of RCA and water /cement ratio values. There is a marginal difference between compressive strength of normal concrete and concrete produced by partial RCA of $15 \%$ replacement at $0.4 \mathrm{w} / \mathrm{c}$ ratio.
\end{abstract}

Keywords: recycled concrete aggregate, natural aggregate, compressive strength, water/ cement ratio and natural aggregate concrete.

\section{INTRODUCTION}

Structures built with concrete need to be repaired or replaced as result of attainment of service life or redesign/modifications. These activities create large stockpiles of demolished concrete which pose environmental hazards all over the world. As a result of dwindling natural resources, such recycled concrete aggregates are being used to make fresh concrete. The recycled aggregate is produced by crushing concrete from demolition sites. However, the quality of the recycled aggregate depends primarily on the origin and quality of the concrete from which it is obtained. The most important property for the prediction of concrete strength is the compressive strength. Compressive strength of hardened concrete is generally determined by destructive testing of controlled specimens in a Compressive Testing Machine (CTM) in the laboratory.

The effect of recycled concrete aggregates (RCA) over some properties of concretes, composition and mix design influence on the concrete were investigated in mixes ranging from 0.45 to $0.6 \mathrm{w} / \mathrm{c}$ ratios, with $0 \%$, $20 \%, 50 \%$ and $100 \%$ coarse aggregates replacement was examined by [1]. The objective of the study was to evaluate the effects of relative proportions of RCA used in concretes, over the chloride diffusion behaviour in order to facilitate the possibility of a more extended use of RCA in structural concrete subject to chloride environments in order to determine the effect of chloride ion. The chloride attack on RAC was performed through the immersion of samples in a chloride sodium was made using $14.2 \%$ of $\mathrm{NaCl}$ per liter of distilled water.

The durability of recycled aggregate concrete was investigated by [2]. The main objective of the work was to define the regulation for the use of recycled aggregates in structural concrete. The study explored the physical properties of concrete made with recycle aggregate which include (density, porosity and water absorption).

The observations were as follows:

\footnotetext{
* Corresponding author, tel: +234-803-310-6918
} 
i. The durability of RAC, cast with the same water/cement ratio is lower than that of the conventional concrete due to higher porosity of recycled aggregate.

ii. The densities of recycled aggregate concrete made with recycled aggregate are below those of the control concrete. This indicates that the densities decrease with the incorporation or addition of recycled aggregate.

A new method for predicting compressive strength of recycled aggregate concrete (RAC) mixtures; which considers some specific properties of the Recycle Concrete Aggregate (RCA) such as the high porosity and water absorption characteristics was investigated by [3]. The rational method also accounted for the effect of RCAs processing procedures, aggregate replacement ratio and initial moisture condition of aggregates. One uniqueness of the method is that, it considers the effective water to cement ratio which accounts for the free water transfer from RCAs in addition to effect of high porosity on the strength of RAC. The time evolution of compressive strength was determined from the attached mortar component of RCAs. But the proposed method is not applicable to the long-term behaviour and other durability aspect of RAC.

The durability performance of concrete with recycled aggregates (RCA) from the construction and demolition waste from various locations in Portugal was investigated by [4]. The effect of recycled concrete aggregate (RCA) over some properties of concrete such as composition and mix design influence on the concrete were investigated in mixes ranging from 0.45 to $0.6 \mathrm{w} / \mathrm{c}$ ratios with $0 \%, 20 \%, 50 \%$ and $100 \%$ coarse aggregate replacement. They concluded that the use of recycled aggregate is detrimental to the quality of hardened concrete in terms of durability in addition; they also observed that carbonation resistance was the property with the worst results from the use of recycled aggregate in concrete.

The rheological behaviour of concrete made with fine recycled concrete aggregates was studied by [5]. Two types of super plasticizers were investigated. It was observed that the incorporation of fine recycled concrete aggregate (FRCA) increases the shrinkage and Creep Deformation significantly. The incorporation of super plasticizers increases the Shrinkage at early ages and decreases the shrinkage at 91 days of age. The use of recycled concrete aggregates (RCA) from two different sources in concrete works was investigated by [6]. The result revealed that both mechanical and durability terms were not significantly influenced by the aggregates sources. They observed that compressive strength of RAC decreases as the replacement ratio increases. Furthermore, the incorporation of RCA was responsible for increases of concrete's water absorption by immersion between $23 \%$ and $49 \%$, among to higher water absorption of the RCA

The effects of recycled coarse aggregates (RCAs) on normal and high performance concrete subjected to high temperature was studied by [7]. The study also compared RCAs from two different sources by considering some influential parameter that influences the mechanical properties such as porosity, compressive strength and tensile strength. It was observed that the elevated temperatures caused a significance loss of mass from the RCA because of higher moisture contents in the aggregates. No significance difference based on the type of RCA given that their compositions were similar.

The damping property of recycled aggregate concrete was investigated by [8]. They investigated the effect of replacement percentage and size of recycled coarse aggregate (RCA) on the damping property of RAC. It was concluded that the replacement percentage and the RCA size have a significance influence on the damping property of RAC.

The durability performance of self-compacting concrete (SCC) made with recycled concrete Aggregates (RCA) was studied by [9]. They observed that the initial surface absorption of the control concrete increased with increase in the RCA content for all the curing ages. In addition, water penetration depths increase with increase in the content of recycled aggregate in the self-compacting concrete.

The effects of recycled aggregate on the modulus of elastically of concrete using statistical analysis of data available in the literature was investigated by [10], the following observations are made.

* The elastic modulus usually decreases with increasing RA content, the degree depths on the quality size type of RCA.

* The modulus of elastically of RCA directly depends on the strength and stiffness of the original materials (RCA).

* In order to produce the Elastic modulus of RAC concrete, effectively based on the size and type of RAC, its quality is significance.

The durability of recycle green building materials in light weight aggregate concrete was studied by [11]. In their study, their light weight aggregate concrete 
namely; fly ash, slag, rubber powder and glass sand are investigated. They observed that the compressive strength of light weight at the age of 7 days and 91 days could be $36 \mathrm{MPa}$ and $56 \mathrm{Mpa}$ respectively. Maximum compressive strength was achieved when the wet glass sand replacement is $5 \%$.

An experimental investigation on the early age behaviour of recycled aggregate concrete was carried out by [12]. The effect of recycled gravel and initial water saturation on plastics shrinkage and cracking was also investigated. The initial water saturation of the RCA does not have any significance influence on plastic shrinkage of RAC. They observed that rate of substitution of recycled aggregates had no significanct effects on the plastic shrinkages. They concluded that the cracking sensitivity is not proportional to the recycles aggregate content.

In this research, compressive strength matrix of RCA concrete for varying percentage replacement ratios and monitored water/cement ratios were developed experimentally. The developed matrix gives a guide on the amount in percentage of recycled concrete aggregate replacement ratio of the conventional chippings and water/ratio for a selected strength characteristic. Use of the matrix will simply help the work of engineers intending to produce concrete using recycled concrete aggregate (RCA).

\section{MATERIAL AND METHODS}

\subsection{Materials}

The following materials were used in this research work.

\subsubsection{Recycled Concrete Aggregate (RCA)}

The used concrete wastes were of concrete characteristic strength of between 25 to $30 \mathrm{MPa}$. The maximum aggregate sizes were $20 \mathrm{~mm}$. They were obtained from building demolition sites in the Rivers State University Port Harcourt.

\subsubsection{Cement}

The cement used is for sample production in this research is the Dangote $3 X$ Portland Lime Stone Cement (PLC) of grade 42.5R conforming to [13]

\subsubsection{Sand}

The fine river sand was obtained from the Choba River in Emohua local government area of Rivers State, Nigeria. Test were conducted in accordance with [14].

\subsubsection{Coarse Aggregate}

Coarse aggregate used was angular and rough textured granite obtained from Crushed Rock Industry Nigeria Limited, Akamkpa in Cross River State, Nigeria. It is of maximum size of $20 \mathrm{~mm}$. Test were conducted in accordance with [15].

\subsubsection{Water}

The general water fit for drinking purposes and conforming to [16] was used.

\subsection{Method}

\subsubsection{Concrete Recycling Process:}

A selection of discarded concrete cubes of compressive strengths between 25 to $30 \mathrm{MPa}$ gathered from the concrete laboratory of the Civil Engineering Department, Rivers State University was fragmented with a mallet to maximum size of $20 \mathrm{~mm}$.

\subsubsection{Sieve Analysis}

The coarse aggregates was poorly graded and do not conform to [17].

\subsubsection{Specific Gravity}

Test on specific gravity (Gs) was conducted in accordance with [18].

\subsubsection{Bulk Density and Unit weight}

Bulk Density and Unit Weight were performed in accordance with [19].

\subsubsection{Workability}

Slump test is the measure of workability; this test was conducted in accordance with [20].

\subsubsection{Concrete production}

A mix ratio of $1: 2: 4$ by weight with varying water/ cement ratios of $0.4,0.45,0.50,0.6$ and 0.65 was used to produce concrete with a replacement ratio of $0 \%, 15 \%, 30 \%, 45 \%, 60 \%$ and $75 \%$ RCA. For each percentage replacement, compressive test was conducted in accordance with [21].

\subsubsection{Water Absorption Test}

This test was carried out in accordance with [22]

\section{RESULTS AND DISCUSSION}

\subsection{Particle Size Distribution}

From Figures 1 and 2, the result of sieve analysis carried out in accordance with [14] for fine particles $(<4.75 \mathrm{~mm})$ aggregate was found to have a 
Investigations of the Structural Characteristics of Concrete Produced from Recycled ..., AW Otunyo \& BG Jephter

percentage passing of $60 \%$ and coarse particle passing of the total recycled aggregate of $30 \%$ falling within size $4.75-20 \mathrm{~mm}$ and about $10 \%$ of the rest falls within the maximum aggregate size of $20 \mathrm{~mm}$. This gradation can be indicated as a zone 3 aggregate.

\subsection{Specific Gravity}

The specific gravity of the cement, fine river sand, NA and RCA are 3.045, 2.70, 2.74 and 2.75 respectively.

\subsection{Density of Concrete}

The relationship between concrete density versus the age of soaking is tabulated in Table 1 . The results indicate corresponding increase in density as the days of soaking is prolonged; this was different for concrete with reduced recycled aggregate inclusion. It can also be deduced from laboratory results that the pores in RCA caused the reduction in concrete weight.
Table 1: Relationship between concrete densities versus age

\begin{tabular}{ccccc}
\hline \multirow{2}{*}{ Age } & \multicolumn{4}{c}{ Concrete Density $\left(\mathrm{kg} / \mathrm{m}^{3}\right)$} \\
\cline { 2 - 5 } (Days) & NCA $(0 \%$ R & $90 \% R$ & $60 \% R$ & $30 \% R$ \\
7 & $27)$ & CA & CA & CA \\
14 & 2700 & 2637 & 2589 & 2525 \\
28 & 2785 & 2649 & 2590 & 2538 \\
\end{tabular}

\subsection{Water Absorption}

Table 2, shows that the percentage water absorption rate increased for every incremental percentage replacement of RCA. The reason was attributed to the presence of intermolecular pores in the concrete having higher recycled aggregate replacement. The results also indicated an increase in mass of the concrete as the soaking days increased, resulting from linear increase in water absorption of the RCA modified concrete. The reason for this result is similar to those established by [ 6 and 9 ].

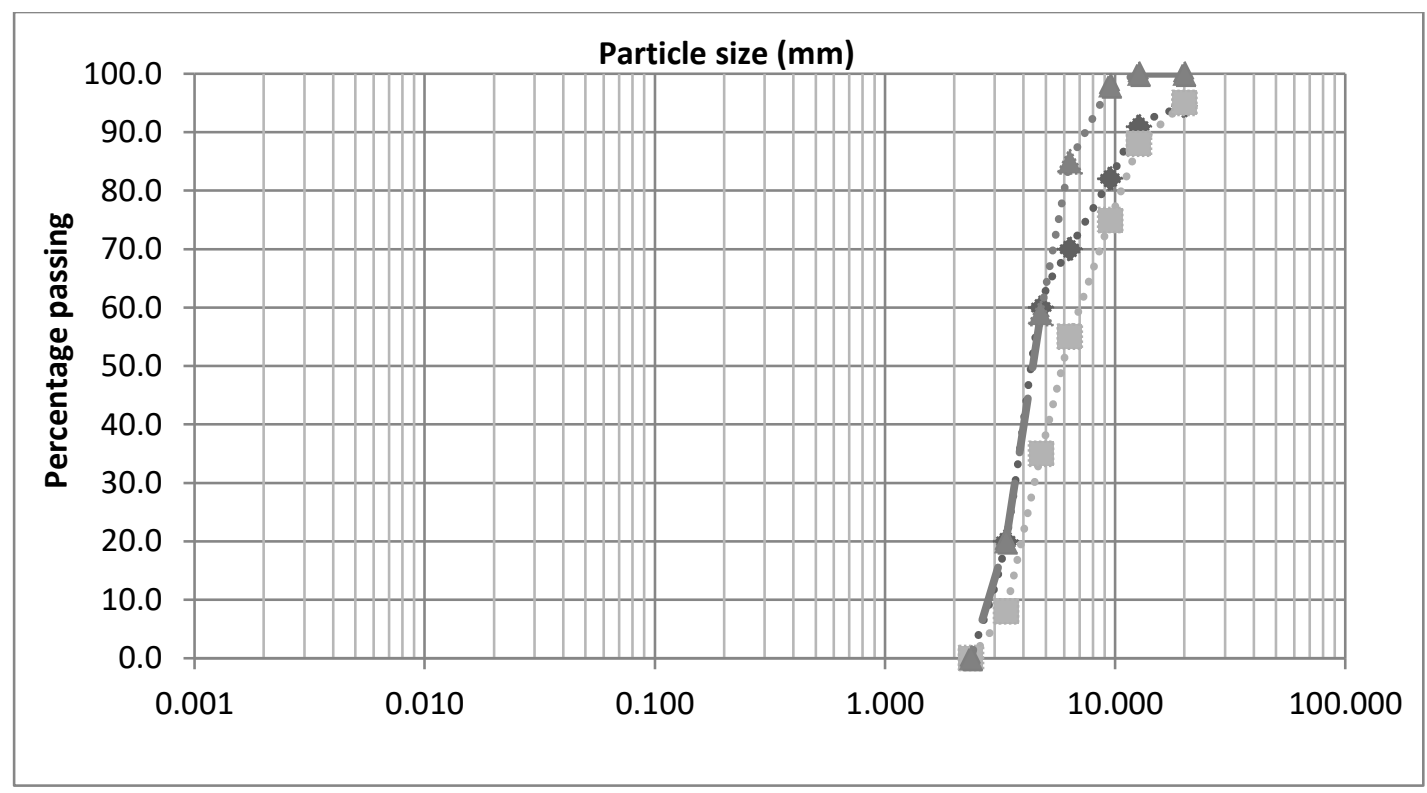

Figure 1: Plot of Particle Size Distribution Graph for Natural Concrete Aggregate

Table 2: Percentage Water Absorption Capacity for 28 Days Old Concrete

\begin{tabular}{ccccc}
\hline \multirow{2}{*}{ Percentage RCA } & \multicolumn{4}{c}{ Percentage Water Absorption Capacity for 28 Days Old Concrete } \\
\cline { 2 - 5 } 90\% RCA & Before Immersion: & Day 1 & Day 5 & Day 9 \\
\cline { 2 - 5 } 60\% RCA & 7.86 & 9.01 & 9.52 & 9.88 \\
$30 \%$ RCA & 7.46 & 8.66 & 9.30 & 9.51 \\
\hline
\end{tabular}




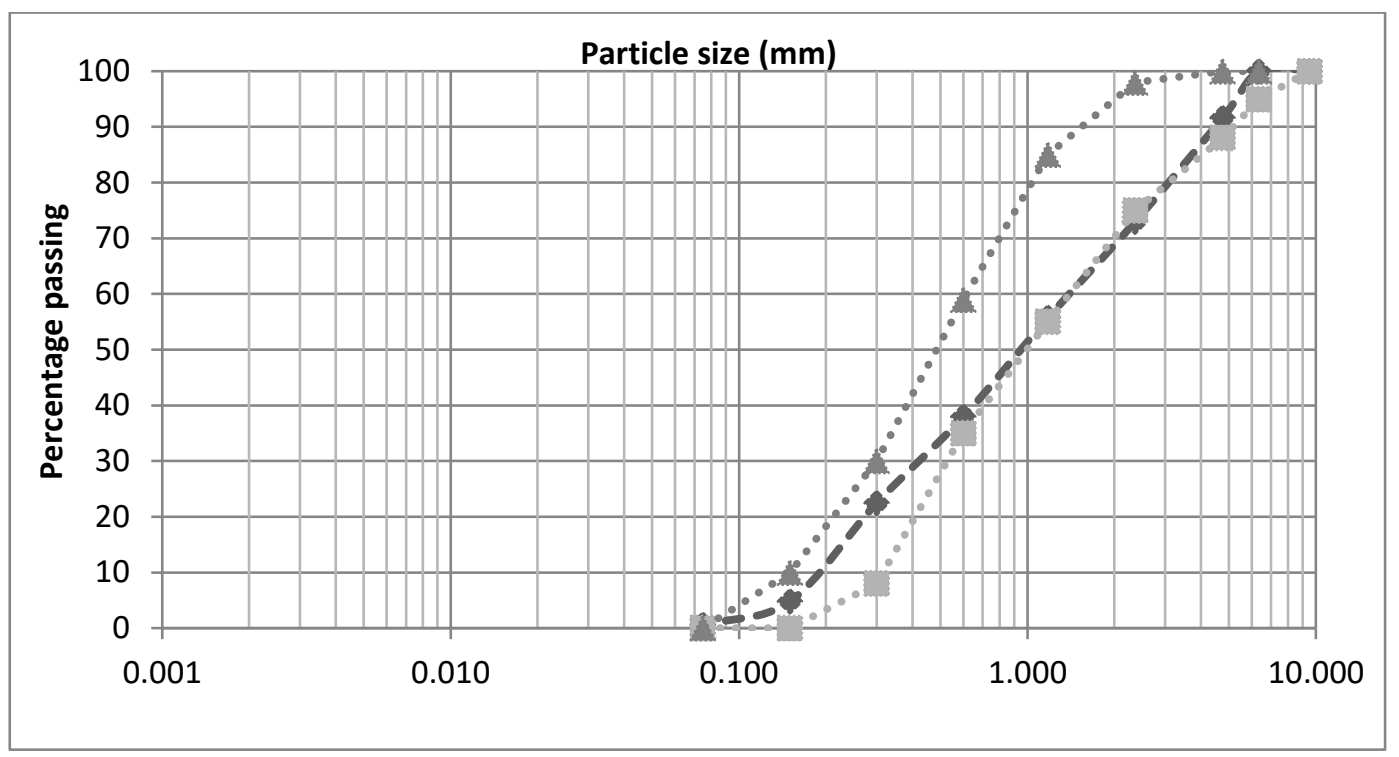

Figure 2: Plot of Particle Size Distribution Graph for Recycled Concrete Aggregate

Table 3: Result of Compressive Strength for Different W/C Ratios

\begin{tabular}{llllllll}
\hline \multirow{2}{*}{ Age (days) } & \multirow{2}{*}{ Series } & \multicolumn{5}{c}{ Water Cement Ratio } \\
\cline { 3 - 7 } 28days & NAC & 34.92 & 33.5 & 30.1 & 27.86 & 24.30 & 21.91 \\
& RCA 15\% & 33.50 & 31.34 & 30.52 & 27.98 & 25.01 & 21.57 \\
& RCA 30\% & 31.52 & 30.34 & 27.22 & 23.31 & 21.98 & 18.97 \\
& RCA 45\% & 28.01 & 25.09 & 24.00 & 21.91 & 18.37 & 17.33 \\
& RCA 60\% & 26.11 & 21.99 & 20.01 & 18.91 & 16.74 & 15.99 \\
& RCA 75\% & 23.74 & 18.86 & 15.11 & 14.00 & 12.40 & 10.81 \\
& RCA 90\% & 20.24 & 16.56 & 13.44 & 10.83 & 8.38 & 7.31 \\
& NAC & 26.63 & 24.72 & 20.21 & 18.10 & 15.55 & 14.00 \\
& & & & & & & \\
& RCA 15\% & 24.13 & 21.97 & 18.88 & 15.00 & 12.23 & 9.33 \\
& RCA 30\% & 20.33 & 18.17 & 16.38 & 13.49 & 9.42 & 7.13 \\
& RCA 45\% & 17.99 & 14.14 & 12.31 & 9.74 & 6.95 & 5.01 \\
& RCA 60\% & 14.00 & 10.91 & 11.34 & 8.24 & 5.47 & 3.04 \\
& RCA 75\% & 13.43 & 9.00 & 8.21 & 6.98 & 4.93 & 2.97 \\
& RCA 90\% & 10.53 & 8.64 & 7.11 & 5.05 & 3.97 & 3.04 \\
& & & & & & & \\
& NAC & 18.69 & 16.99 & 15.04 & 13.91 & 13.06 & 12.57 \\
& RCA 15\% & 8.03 & 5.91 & 4.81 & 3.41 & 2.91 & 2.76 \\
& RCA 30\% & 7.97 & 5.64 & 4.34 & 3.03 & 2.87 & 2.70 \\
& RCA 45\% & 7.00 & 5.36 & 4.30 & 2.90 & 2.70 & 2.57 \\
& RCA 60\% & 6.61 & 4.87 & 3.91 & 2.45 & 2.20 & 2.00 \\
& RCA 75\% & 5.54 & 4.63 & 3.51 & 2.03 & 1.09 & 1.74 \\
& RCA 90\% & 4.51 & 3.64 & 2.02 & 1.33 & 1.26 & 1.09 \\
\hline
\end{tabular}

\subsection{Compressive Strength}

The compressive strength at (7, 14 and 28 days) results of all mixes are presented in Table 3. Each mix result was obtained from average compressive strengths of three cubes. It is noticed that there is an appreciable increase in compressive strength of RAC as the water/cement ratio is lowered. Results also indicates that at 28days test, using water/ cement ratio of 0.4 and $15 \%$ RCA replacement of chippings, a compressive strength of $33.50 \mathrm{MPa}$ is achieved. The 
increase in compressive strength is attributed to a reduction in water/ cement ratio RCA replacement ratio.

The results in Figures 3, 4 and 5 depicts a correlation between the compressive strength, RA replacement and water cement ratio. The curve patterns are similar to that of a conventional concrete where for a degree of hydration, the water cement ratio determines the porosity of the cement gel which further influences the strength of the concrete. From the figures, the compressive strength of RCA increased with decrease in water/ cement content and minimized aggregate replacement. The reduction in compressive strength also confirmed the earlier results by previous researchers that established the compressive strength of RCA concrete is about two-third that of the virgin aggregate concrete [23]. The decrease can be attributed to weaker interface between the recycled concrete aggregate (RCA) which is surrounded by residual cementatious matrix of cement and sand before the new concrete mix; other possible reasons for reduction in compressive strength include the flakiness and angularity of the RCA which makes compaction limited and hence reduced bulk density [24].

\section{CONCLUSION}

Series of concrete mixes were developed with the aim of establishing a mix matrix for the selection of a required compressive strength. The following conclusions were made from results of this study:

i. Results indicate increased compressive strength at a reduced \%RCA and water /cement ratio values.

ii. There exists a negligible variance between compressive strength of normal concrete and RCA of $15 \%$ replacement with $0.4 \mathrm{w} / \mathrm{c}$ ratio.

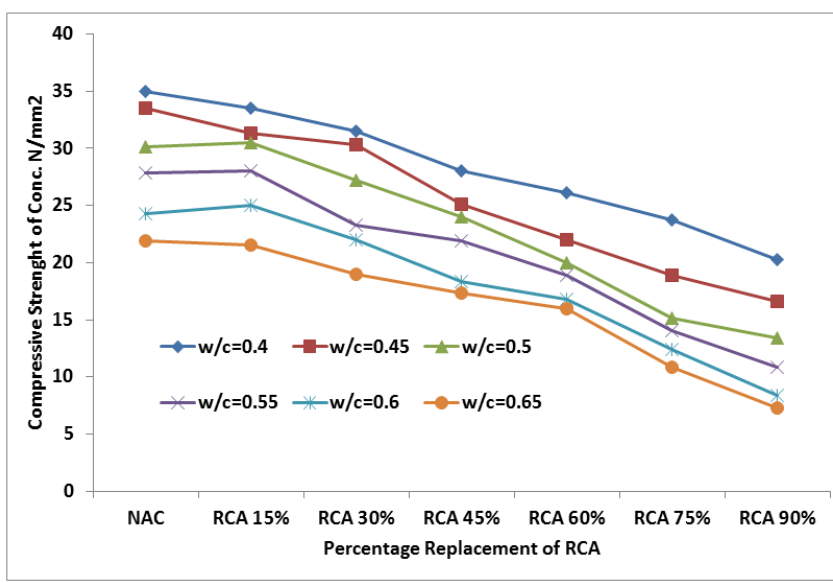

Figure 3: Compressive Strength of RCA for Varying Water Cement Ratios at 28 Days

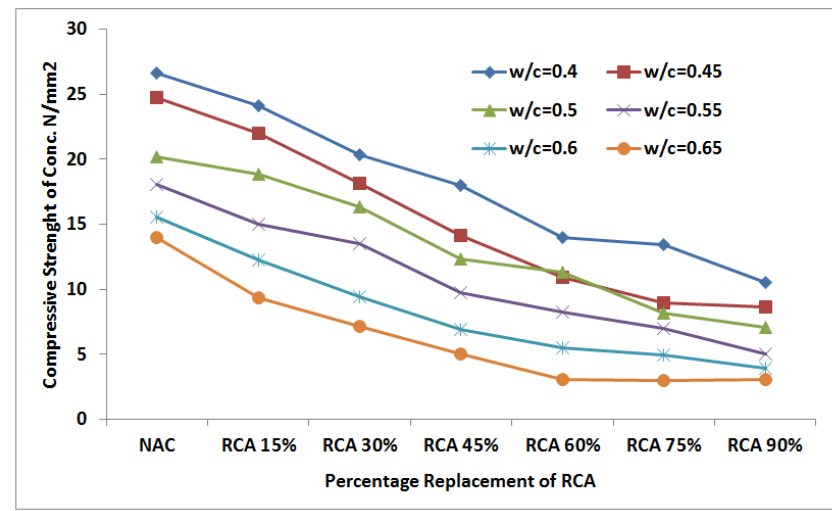

Figure 4: Compressive Strength of RCA for Varying Water Cement Ratios at 14 Days

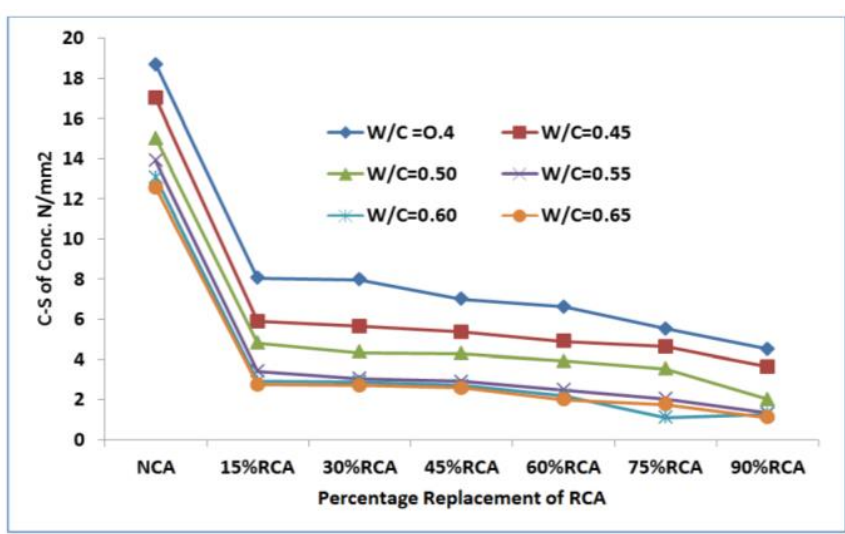

Figure 5: Compressive Strength of RCA for Varying Water Cement Ratios at 7 Days

\section{REFERENCES}

[1] Caijun, S., Yake L., Jiake Z., Wengui L., Linlin C., and Zhaobin, X. Performance Enhancement of Recycled Concrete Aggregate. A Review Journal of Cleaner Production, Vol. 11. pp. 466-472, 2016.

[2] Thomas, C. J., Setien, J. A., Polanco, P. and Alae, J. Durability of Recycled Aggregate Concrete. Construction and Building Materials. Vol. 71, pp. 141-151, 2013.

[3] Pepe M., Dias T. F Romildo. Koenders E.A.B, Martinelli E.. A Novel Mix Design Methodology for Recycled Aggregate Concrete. Construction and Building Materials Vol.122, pp 362-372, 2016.

[4] Miguel, B., Jorge de B., Jorge P.and Luís E. Durability Performance of Concrete with Recycled Aggregate from Construction and Demolition Waste Plants. Construction and Building Materials Vol.111, pp 357-369, 2015.

[5] Cartuxo F., de Brito J., Evangelista L., Jimenez J. R. J., Ledesima E. F. Rheological Behaviour of Concrete Made with Fine Recycled Concrete 
Investigations of the Structural Characteristics of Concrete Produced from Recycled ..., AW Otunyo \& BG Jephter

Aggregates - Influence of the Superplastisticizer. Construction and Building Materials. Vol. 89, pp 36-47, 2015.

[6] Pedro, .D, de Brito, J. and Evangelista L. Influence of the Use of Recycled Concrete Aggregates from Different Sources on Structural Concrete. Construction and Building Materials. Vol. 71, pp. 141-151, 2014.

[7] Laneyrie, C., Anne-Lise, B., Mark, F. G. and Ronan, L. Influence of recycled coarse aggregate on normal and high-performance concrete subjected to elevated temperatures. Construction and Building Materials. Vol. 111, pp. 368-378, 2016.

[8] Liang, C., Liu, T. and Xiao, J. The damping property of recycled aggregate concrete. Construction and Building Materials. Vol. 102, pp.834-842, 2016.

[9] Kapook. S. S.P. and Singh, B. Durability of selfcompacting concrete made with recycled concrete aggregates and mineral admixtures. Construction and Building Materials. Vol. 128, pp. 67-76, 2016.

[10] Silvam R. V., de Brito, J. and Ravinddra, K. D. Establishing a relationship between modulus of elasticity and compressive strength of recycled aggregate concrete. Journal of Cleaner Production. Vol. 112, pp.2171-2186, 2016.

[11] Li-Jeng, H., Her-Yung, W. and Shi-Yang, W. A Study of the durability of recycled green building materials in lightweight aggregate concrete. Construction and Building Materials. Vol. 96, 2015, pp.353-359.

[12] Ahmed, Z. B, Emmanuel. R. and Ahmed, L. Plastic shrinkage and cracking risk of recycled aggregate concrete. Construction and Building Materials. Vol. 121, pp.733-745, 2016.

[13] BS 4550 Part 1: Method of Testing Cement; Sampling. British Standards Institute, London United Kingdom, 1978.

[14] BS 812-103.1: Methods for Testing Fine Aggregate. British Standards Institute, London United Kingdom, 1985.
[15] BS 812-103.2: Methods for Testing Coarse Aggregate. British Standards Institute, London United Kingdom, 1989.

[16] ASTM C1602/ C1602 M-06: Standard specification for mixing water used for hydraulic cement concrete. American Standards for Testing of Materials International, West Conshohocken, PA 19438-2957, 2006.

[17] BS 812-103.1: Testing aggregates, Methods for determination of particle size distribution; sieve test. British Standards Institute, London United Kingdom, 1985.

[18] ASTM D 854-10: Standard Test Methods for Specific Gravity of Soils by Water Pycnometer. American Standards for Testing of Materials International. West Conshohocken, PA 194382957, 2010.

[19] ASTM D7263-09: Standard Test Method for laboratory Determination of Density (Unit Weight) of specimen. American Standards for Testing of Materials, 2018.

[20] BS 1881; Part 102: Testing Concrete. Method of determination of slump. British Standards Institute, London United Kingdom, 1983.

[21] BS 1881-Part 108\&116: Method for making test cubes from fresh concrete \& Method for determination of compressive strength of concrete. British Standards Institute, London, United Kingdom, 1983.

[22] ASTM D 2216: Standard Test Method for laboratory Determination of Water Content in Soil- Oven Drying Method. American Standards for Testing of Materials International. West Conshohocken, PA 19438-2957, 2010.

[23] Frandistou-Yannas, S. Tests on waste concrete as aggregates for new concrete. Journal of American Concrete Institute, Vol. 74, No. 8, pp. 373-376, 1977.

[24] Uche, O.A.U. Influence of recycled concrete aggregate (RCA) on compressive strength of plain concrete. Continental Journal of Engineering Sciences, Vol. 3, pp. 30-36, 2008. 